\title{
Flexible Dual-Frequency Applicator for Local Hyperthermia
}

\author{
Houda Halheit, ${ }^{1}$ André Vander Vorst, ${ }^{2}$ Smail Tedjini, ${ }^{3}$ and Rachida Touhami ${ }^{1}$ \\ ${ }^{1}$ Instrumentation Laboratory, Faculté d'Electronique et d'Informatique, Université USTHB, BP 32, El Alia, Bab-Ezzouar, \\ 16111 Algiers, Algeria \\ ${ }^{2}$ Microwave Laboratory, UCL University, Batiment Maxwell, 3 Place du Levant, P.O. Box 1348, Belgium \\ ${ }^{3}$ LCIS Laboratory, ESISAR, Grenoble INP, 50 Rue B. de Laffemas, BP 54, 26902 Valence, France
}

Correspondence should be addressed to Houda Halheit, h.halheit@gmail.com

Received 30 March 2012; Accepted 4 June 2012

Academic Editor: Ahmed A. Kishk

Copyright ( $) 2012$ Houda Halheit et al. This is an open access article distributed under the Creative Commons Attribution License, which permits unrestricted use, distribution, and reproduction in any medium, provided the original work is properly cited.

\begin{abstract}
A flexible and dual-frequency microstrip applicator for microwave local hyperthermia is described. It is designed on conformal liquid crystal polymer (LCP) substrate and operating at ISM (Industrial, Scientific and Medical) frequencies of $915 \mathrm{MHz}$ and 2.45 GHz. To conform the body's curvature, the applicator is bent on a cylindrical body. 3D electromagnetic CST Microwave Studio was used to determine the performance of the applicator and to evaluate the specific absorption rate (SAR) distribution in cylindrical human body phantom. The results obtained show that the antenna can be used in curved situation for uniform and superficial treatment.
\end{abstract}

\section{Introduction}

Hyperthermia is the name given to one of the medical treatments for cancer to heat tumors up to therapeutic temperatures $\left(43-45^{\circ} \mathrm{C}\right)$ without overheating the surrounding normal tissue. The basic principle of the hyperthermia treatment is based on the fact that the tumor tissue is more sensitive to heating in comparison to healthy tissue because of their different vascularisation. For treatment of tumors which are located on the surface of the body, or close to it, the electromagnetic field energy is applied through external antennas (applicators).

There are many references appearing in the subject of hyperthermia applicator [1-5], but very little work has proposed the design of dual-frequency antennas operating in ISM (Industrial, Scientific, and Medical) band [6]. The applicator proposed in this paper is a multilayer dual-frequency rectangular microstrip applicator which is designed for the working ISM frequencies of $915 \mathrm{MHz}$ and $2.45 \mathrm{GHz}$. Microstrip structures prove to be very useful in realization of hyperthermia applicators: in fact they offer the advantage of being potentially cheap, easy to manufacture, and light. In addition, the antenna is flexible and can easily conform itself to various therapeutical situations thanks to the liquid crystal polymer (LCP) substrate. The techniques used to achieve multiple resonance frequencies are addition of parasitic elements and the use of two coaxial feeds.

First, we designed two single patch rectangular applicators for the operating frequencies of $915 \mathrm{MHz}$ and $2.45 \mathrm{GHz}$, respectively, and then associated them on a common ground plane to achieve the dual-frequency operation and design a double-patch multilayer microstrip applicator. To evaluate these designs under clinical situation, the applicators are bent on a cylindrical body shape. A silicone oil bolus is placed between the applicators and the body in order to avoid possible cutaneous burns.

By means of the simulation using CST Microwave Studio software based on the finite integration technique (FIT), the antennas were designed and studied. Their performances are determined for curved situation. We investigated the effect of the bolus thickness and the body's curvature on the return loss. The last step of the study concerns the SAR (specific absorbed rate) distribution inside the biological tissue and the penetration depth $(\mathrm{PD})$ of the heating.

\section{Antennas Design}

Conformal single and dual-frequency rectangular microstrip applicators are designed using a flexible LCP substrate of 


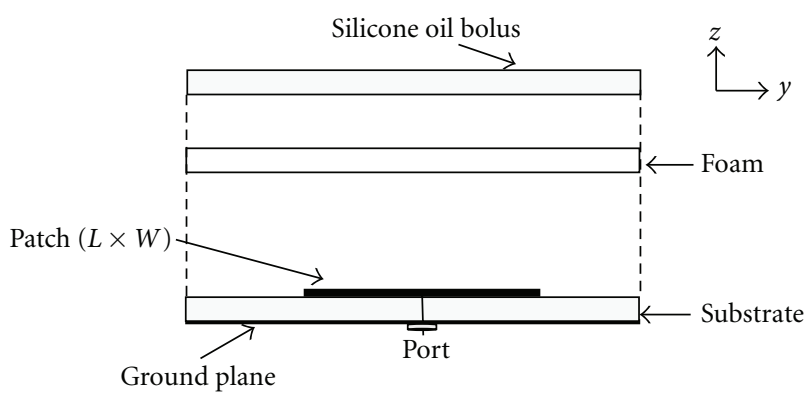

Figure 1: Geometry of the single applicators.

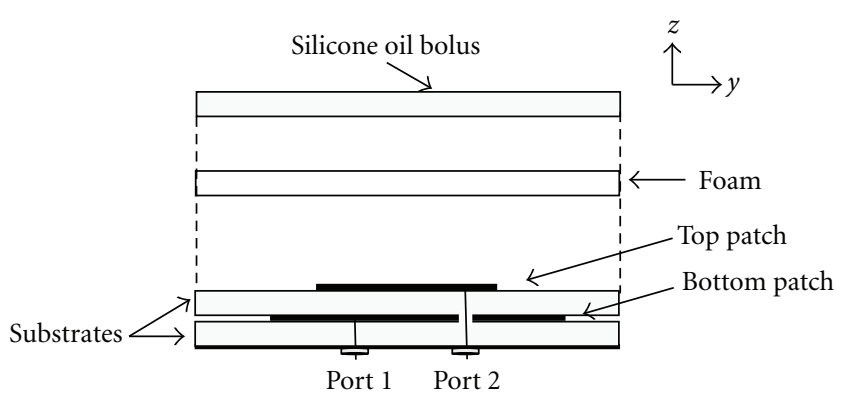

(a)

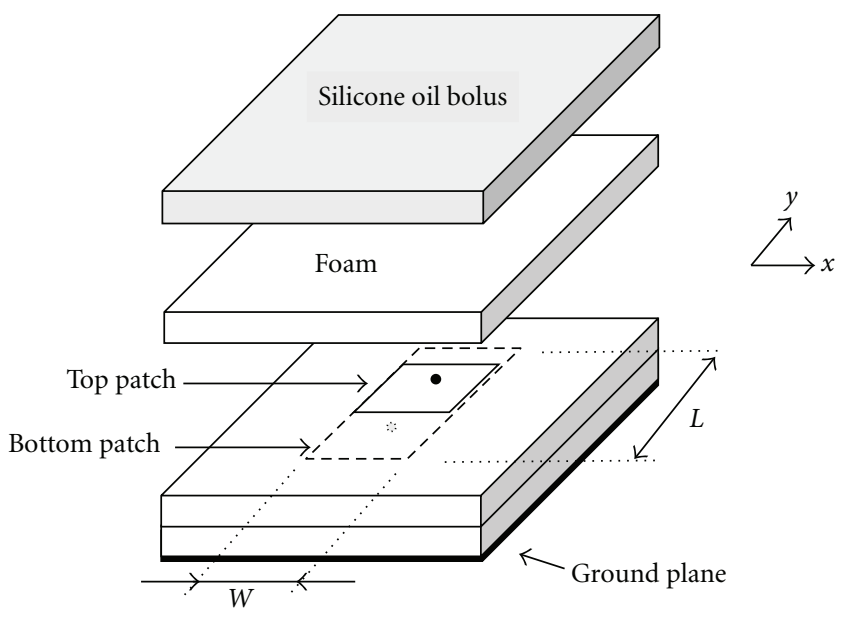

(b)

Figure 2: Geometry of the dual-frequency applicator. (a) Side view. (b) Perspective view.

dimensions $120 \mathrm{~mm} \times 120 \mathrm{~mm}$ with a thickness of $h=$ $2.007 \mathrm{~mm}$, relative dielectric permittivity $\varepsilon_{r}=3.1$, and loss tangent $(\tan \delta)$ of 0.002 .

A liquid dielectric (silicone oil) bolus contained in malleable plastic pocket is placed between the applicator and the body. It allows to keep a good contact between the microwave applicator and the patient in order to protect the surface against the eventually hotspots created by the applicator. The silicone oil bolus was simulated using a material with permittivity $\varepsilon_{r}=2.71$ and conductivity $\sigma=$ $1 \mathrm{e}^{-13} \mathrm{~S} / \mathrm{m}$ [7]. For our simulation, the bolus was taken as rectangular, and the effects of its envelope are neglected.

First, two rectangular microstrip applicators are designed to operate at $915 \mathrm{MHz}$ and $2.45 \mathrm{GHz}$, respectively. The applicators are excited using a single probe feed as shown in Figure 1. A foam material is introduced between the patch and the bolus to enhance the impedance match between the applicator and the body load.

The feed position $(x i, y i)=(0, y i)$ of the port is placed along the $y$ axis of the patch for the excitation of the fundamental mode of $\mathrm{TM}_{10}$. The position of feeding point is optimized along the $y$ axis in order to achieve the best impedance matching when the applicator is placed on the bolus which is followed by the cylindrical human body phantom. The dimensions of the applicators and the optimal
TABLE 1: Antennas dimensions and feed positions.

\begin{tabular}{lccc}
\hline & $\begin{array}{c}\text { Frequency } \\
(\mathrm{GHz})\end{array}$ & $\begin{array}{c}L \times W \\
\left(\mathrm{~mm}^{2}\right)\end{array}$ & $\begin{array}{c}\text { Feed positions } \\
(\mathrm{mm})\end{array}$ \\
\hline Single applicator 1 & 0.915 & $93.20 \times 32$ & $(0,6)$ \\
Single applicator 2 & 2.45 & $33.38 \times 32$ & $(0,-16)$ \\
Dual-frequency applicator & 0.915 & $91.10 \times 32$ & $(0,7)$ \\
& 2.45 & $33.75 \times 32$ & $(0,-16)$ \\
\hline
\end{tabular}

positions of the feeds are given in Table 1. The resonant conditions can be shifted by changing the dimensions of the patches.

The dual-frequency applicator which covers the working frequencies of $915 \mathrm{MHz}$ and $2.45 \mathrm{GHz}$ is shown in Figure 2. The dual-frequency response is achieved by using the association of the single applicators given previously. Slight changes of the values of the resonance frequencies were expected from the values of the single patch applicators calculated previously. In order to fit this variation and to optimize the dimension of the double patch applicator, computer simulations were used. The applicator is excited using dual coaxial probes. The bottom patch is fed with a coaxial probe protruding the first substrate. The coaxial 


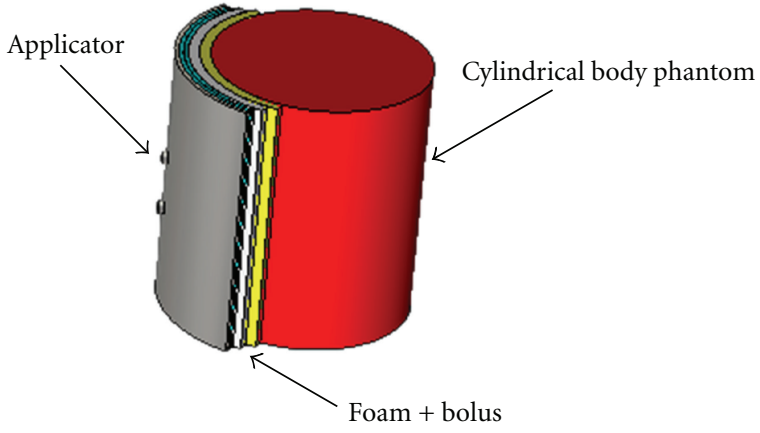

FIGURE 3: The flexible applicator mounted on a cylindrical body.

TABLE 2: Body model dielectric parameters.

\begin{tabular}{lcc}
\hline Frequency $(\mathrm{GHz})$ & $\varepsilon_{r}$ & $\sigma(\mathrm{S} / \mathrm{m})$ \\
\hline 0.915 & 68.898 & 1.6406 \\
2.45 & 68.208 & 2.4781 \\
\hline
\end{tabular}

probe of the top patch passes through the bottom patch and the substrates. The bottom patch is not directly connected with the probe; instead a small hole is made around the feed. The dimensions of the dual-frequency rectangular patches and the positions of the feeds are given in Table 1.

The biological tissue was simulated with a cylindrical human body, whose characteristics are given in Table 2 [8]. Figure 3 shows the dual-frequency applicator placed on the bolus and mounted on the cylindrical body load.

\section{Results}

The electrical performance of the antenna is characterized in terms of simulated return loss, the SAR distribution, and effective depth (PD).

3.1. Return Loss. Good impedance matching at its working frequencies is provided by the choice of an appropriate position of the feeding point and by the dimensions of the antenna.

The simulated return loss of the single patch applicators is presented in Figures 4 and 5. Good impedance matching is obtained between the applicator and the human body phantom. The figures show the maximum return loss of $-28 \mathrm{~dB}$ and $-34 \mathrm{~dB}$ for the antennas at the working frequencies of $915 \mathrm{MHz}$ and $2.45 \mathrm{GHz}$, respectively. The bolus thickness (hsi) and the cylindrical body radius (rb) are chosen to be $5 \mathrm{~mm}$ and $50 \mathrm{~mm}$, respectively.

For the case of dual-frequency applicator, two simulations were performed, one with the feed 1 (feed 2 OFF) for the working frequency of $915 \mathrm{MHz}$ and another with the feed 2 (feed 1 OFF) for $2.45 \mathrm{GHz}$ frequency. Figures 6(a) and 6(b) give the dual-frequency applicator return loss with various bolus thicknesses. By varying hsi from 2.5 to $10 \mathrm{~mm}$, dual-frequency operation is always obtained. It is observed

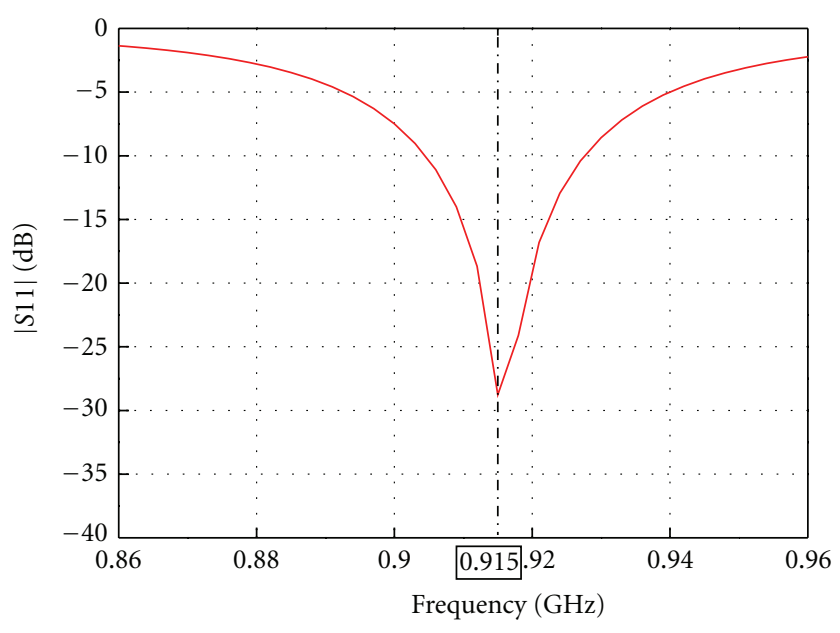

$-S 11=-28.77$

FIGURE 4: $S 11$ with frequency of single applicator $(f=915 \mathrm{MHz})$.

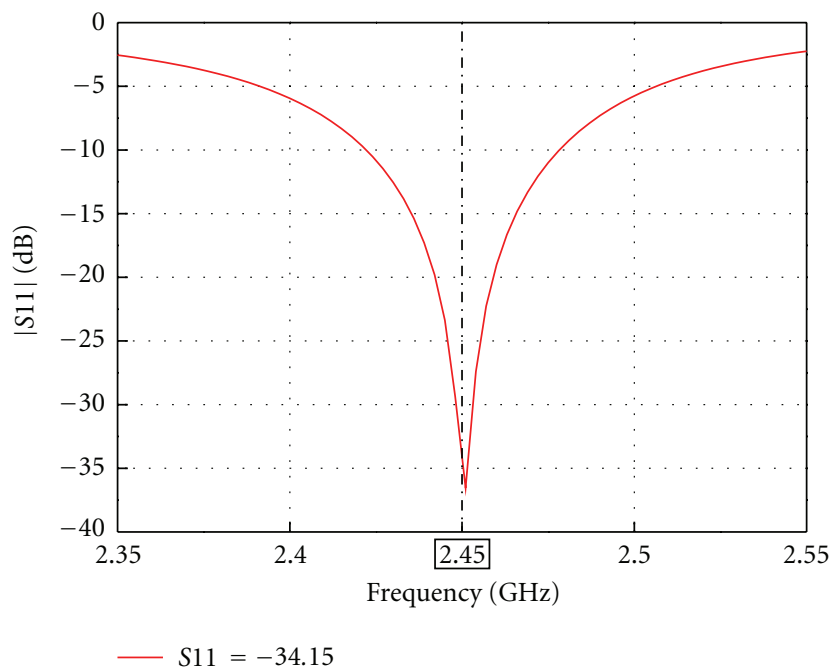

FIGURE 5: $S 11$ with frequency of single applicator $(f=2.45 \mathrm{GHz})$.

that the lower resonant frequency $915 \mathrm{MHz}$ is insensitive to variations in the bolus thickness. The higher operating frequency $2.45 \mathrm{GHz}$ is slightly sensitive to these variations. The best simulated results for both resonances frequencies are found for a fixed value of hsi $=5 \mathrm{~mm}$.

In order to see the impact of bending the antenna on return loss, numerical simulations were performed by varying the cylindrical body radius rb from 25 to $100 \mathrm{~mm}$. Figures 7(a) and 7(b) show that the variation has an insignificant impact for both working frequencies.

3.2. Specific Absorption Rate (SAR). The parameters commonly used in superficial hyperthermia applicable to curved situation are SAR distribution and penetration depth (PD). 


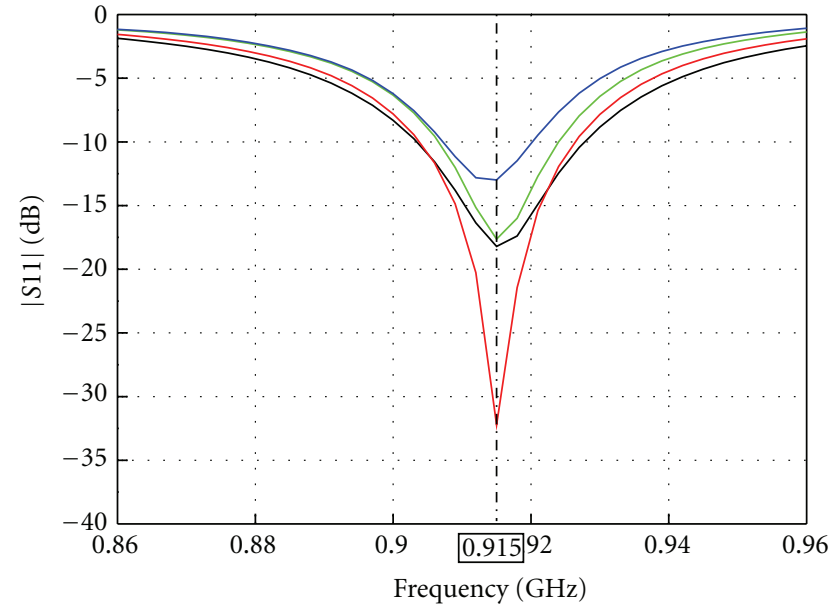

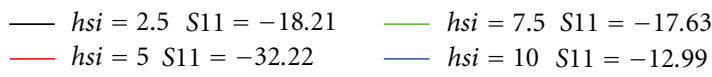

(a)

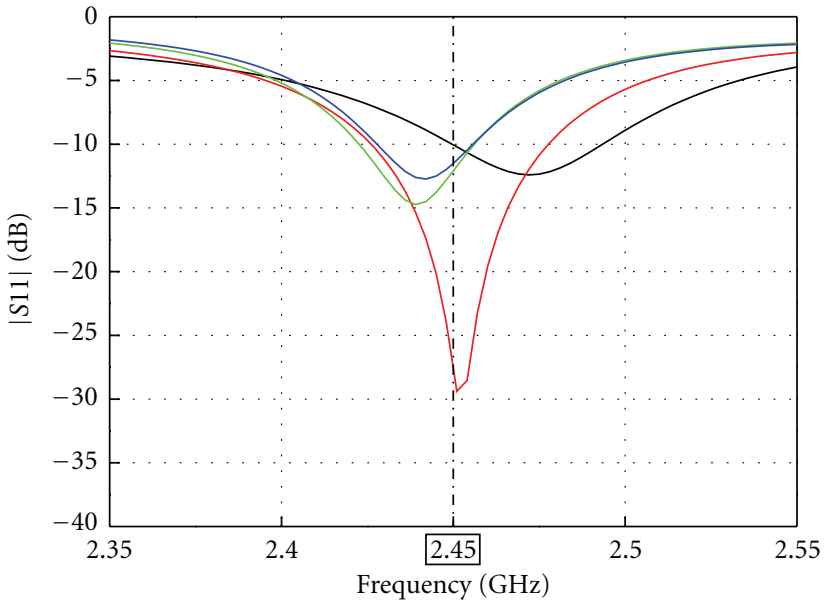

$-h s i=2.5 S 11=-10.06 \quad-h s i=7.5 \quad S 11=-12.08$

(b)

Figure 6: $S 11$ of dual-frequency applicator for different hsi. (a) ( $f=915 \mathrm{MHz})$. (b) ( $f=2.45 \mathrm{MHz}$ ).

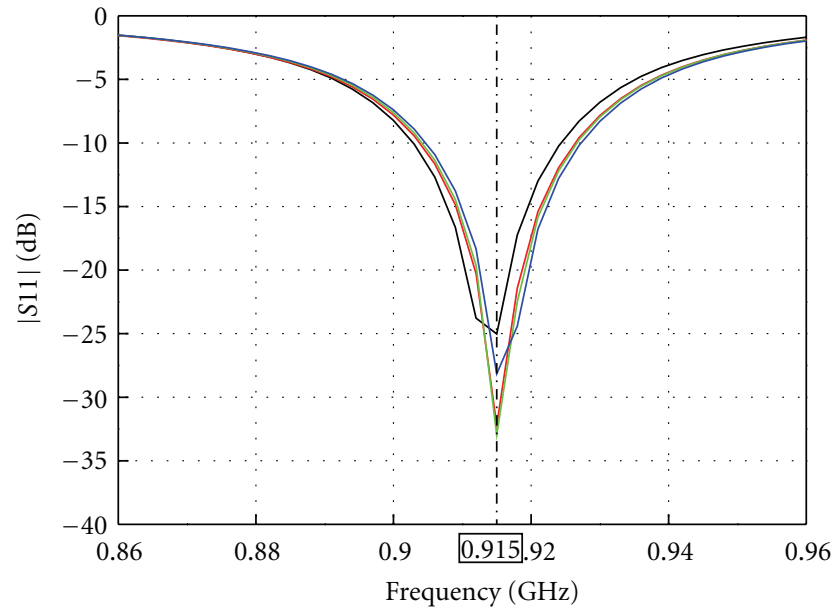

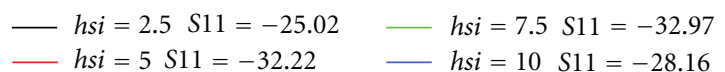

(a)

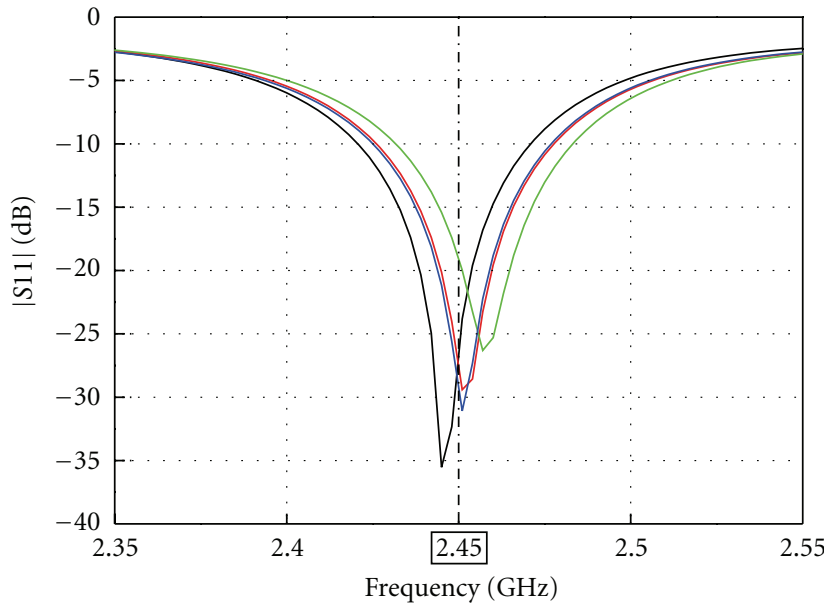

$\begin{array}{ll}-h s i=2.5 S 11=-26.65 \quad-h s i=7.5 \quad S 11=-19.12 \\ -h s i=5 \text { S } & \text { - } 11=-27.62 \quad h s i=10 \quad S 11=-29.26\end{array}$

(b)

Figure 7: $S 11$ of dual-frequency applicator for different rb. (a) $(f=915 \mathrm{MHz})$. (b) $(f=2.45 \mathrm{GHz})$.

The specific absorption rate (SAR) quantifies the power absorption per unit mass of tissue [9]. This quantity is defined as

$$
\operatorname{SAR}=\frac{\sigma}{2 \rho}|E|^{2},
$$

where $\rho\left(\mathrm{kg} / \mathrm{m}^{3}\right)$ and $\sigma(\mathrm{V} / \mathrm{m})$ are the body tissue density and conductivity, respectively. $E(\mathrm{~V} / \mathrm{m})$ is the $\mathrm{rms}$ value of the electric field strength in the tissue.
Simulations results of $1 \mathrm{~g}$ averaged peak SAR are performed to estimate the SAR in the human body, with resistivity $\rho=1000 \mathrm{~kg} / \mathrm{m}^{3}$, exposed to $1 \mathrm{~W}$ microwave source.

The PD is defined as the additional depth at which the SAR has decreased to $50 \%$ of the maximum value at $1 \mathrm{~cm}$ depth [10].

Figures 8, 9, 10(a), and 10(b) show the SAR distribution on the surface of the cylindrical body phantom for the single and for the double patch applicators at a fixed values of the bolus thickness hsi $=5 \mathrm{~mm}$ and the cylindrical body radius 


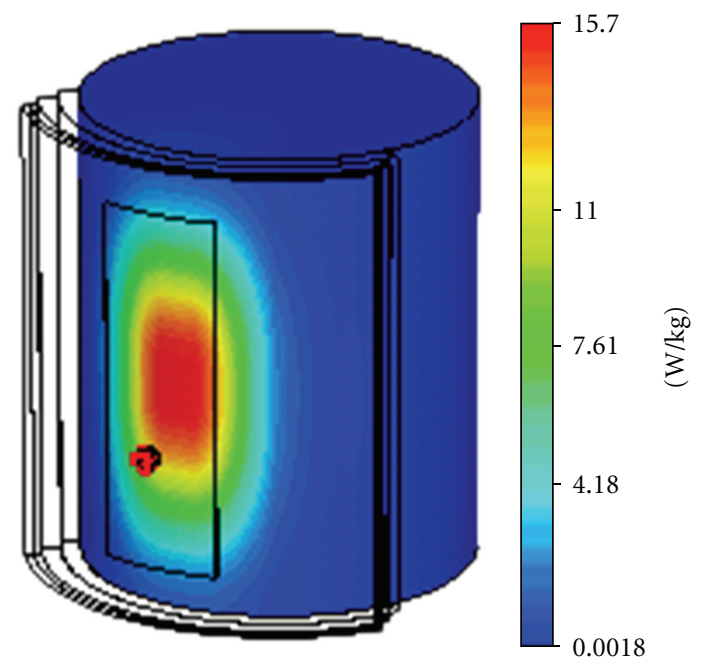

FIGURE 8: SAR distribution of the single applicator $(f=915 \mathrm{MHz})$.

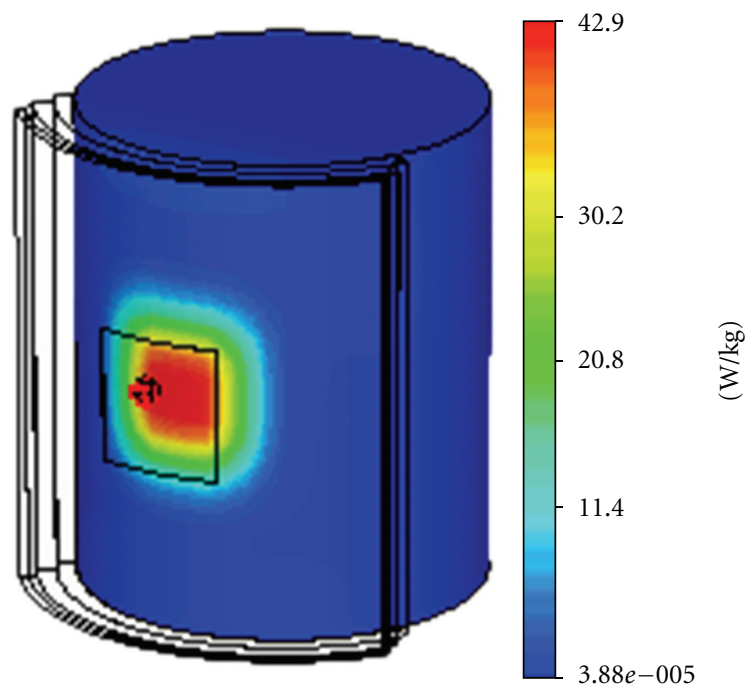

FIGURE 9: SAR distribution of the single applicator $(f=2.45 \mathrm{GHz})$.

$\mathrm{rb}=50 \mathrm{~mm}$. From these results, we notice a good uniformity of SAR distribution for all applicators.

Figures 11(a), 11(b), 12(a), and 12(b), show the SAR distribution inside the phantom considering a cutting plane passing through the center of the applicator obtained in $y z$ plane and $x z$ plane. From these results, we evaluate the penetration depth PD of the treatment. The first cut shows the results at $x=0 \mathrm{~mm}$, exactly on the $y$ axis where the feeds are aligned and where the SAR is the highest. The second cut is selected at $y=0 \mathrm{~mm}$, where the SAR is the highest too. We notice the symmetrical distribution of the SAR.

Table 3 shows the results of maximum SAR and the penetration depth for all applicators. The results show how penetration is not dependent on the bolus thickness and the body curvature. However, the body's curvature has an impact on the maximum SAR especially for the working frequency of $2.45 \mathrm{GHz}$.

As expected, the SAR obtained at $915 \mathrm{MHz}$ in the dualfrequency applicator is below than those of the single patch applicators. The maximum SAR decreases as the antenna moves away from the body. Also the choice of the high working frequency of $2.45 \mathrm{GHz}$ reduces slightly the penetration of the treatment in the tissue compared to the used frequency $915 \mathrm{MHz}$.

\section{Conclusions}

We have presented the study of a flexible dual-frequency applicator to be used for superficial microwave heating in medical application. 


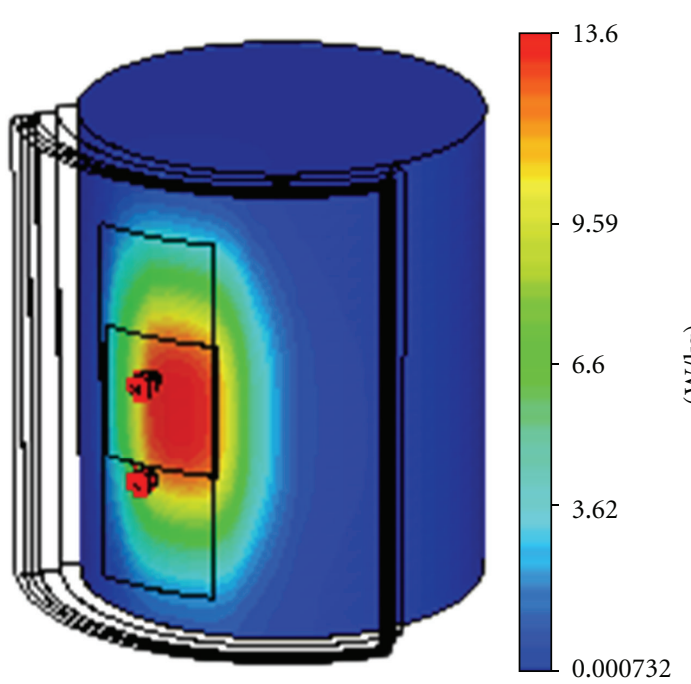

(a)

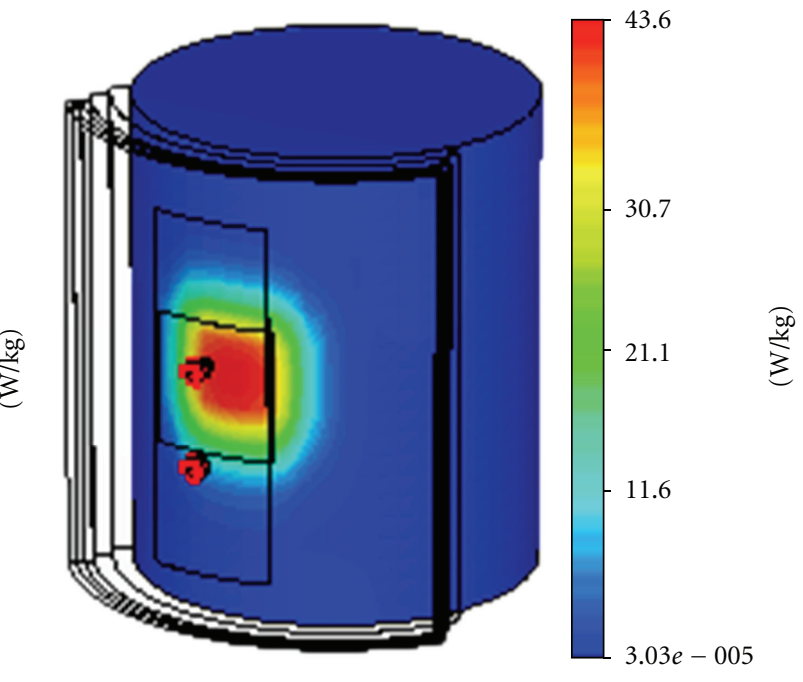

(b)

FigURE 10: SAR distribution of the dual-frequency applicator. (a) ( $f=915 \mathrm{MHz})$. (b) $(f=2.45 \mathrm{GHz})$.

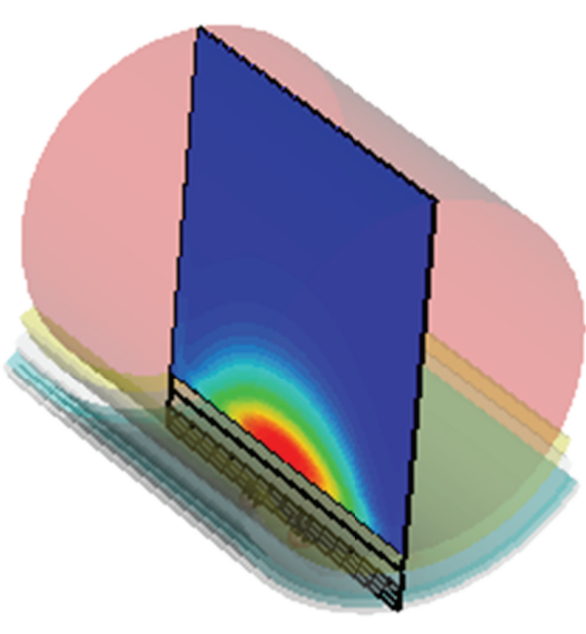

(a)
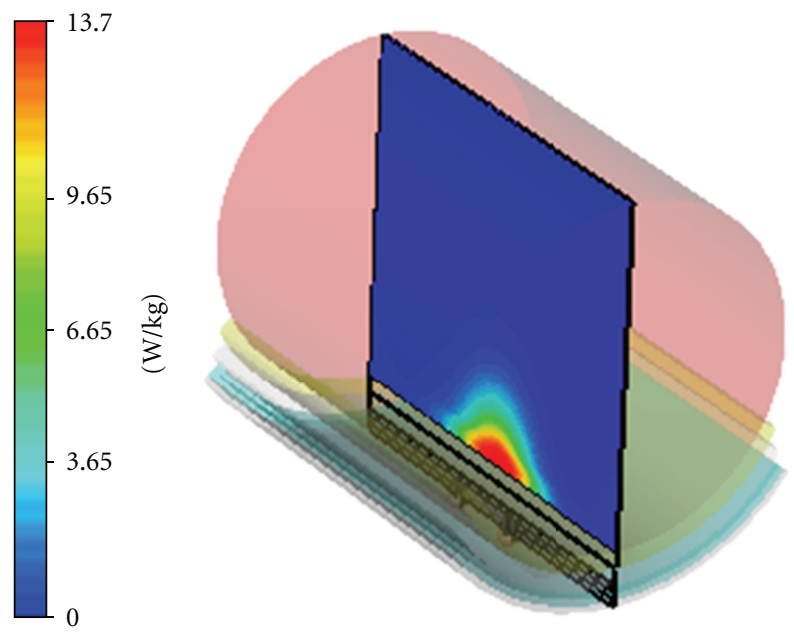

(b)

FIGURE 11: SAR distribution of the multifrequency applicator. (a) $y z$ plane, $f=915 \mathrm{MHz}$. (b) $y z$ plane, $f=2.45 \mathrm{GHz}$.

TABLE 3: SAR and PD values.

\begin{tabular}{|c|c|c|c|c|c|}
\hline Applicators & Frequency $(\mathrm{GHz})$ & $\mathrm{rb}(\mathrm{mm})$ & hsi (mm) & $\mathrm{SAR}_{\max }(\mathrm{W} / \mathrm{Kg})$ & $\mathrm{PD}(\mathrm{mm})$ \\
\hline Single applicator 1 & 0.915 & 50 & 5 & 15.77 & 18 \\
\hline Single applicator 2 & 2.45 & 50 & 5 & 43.18 & 16 \\
\hline \multirow{8}{*}{ Dual-frequency applicator } & \multirow{2}{*}{0.915} & \multirow{2}{*}{50} & 5 & 13.72 & 18 \\
\hline & & & 10 & 10.02 & 18 \\
\hline & \multirow{2}{*}{2.45} & \multirow{2}{*}{50} & 5 & 43.90 & 17 \\
\hline & & & 10 & 40.16 & 16 \\
\hline & \multirow{2}{*}{0.915} & \multirow{2}{*}{100} & 5 & 11.17 & 18 \\
\hline & & & 10 & 7.94 & 18 \\
\hline & \multirow{2}{*}{2.45} & \multirow{2}{*}{100} & 5 & 27.93 & 17 \\
\hline & & & 10 & 12.85 & 16 \\
\hline
\end{tabular}




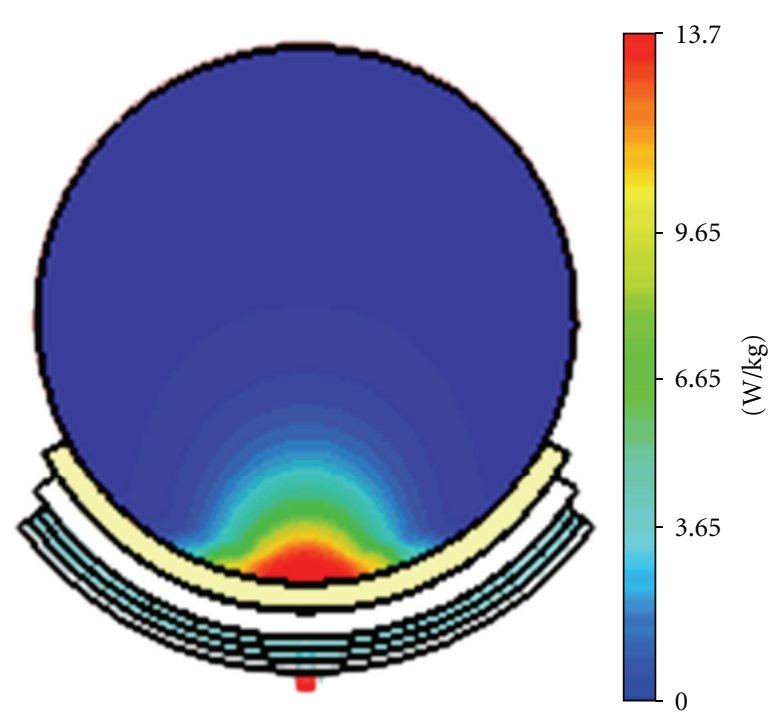

(a)

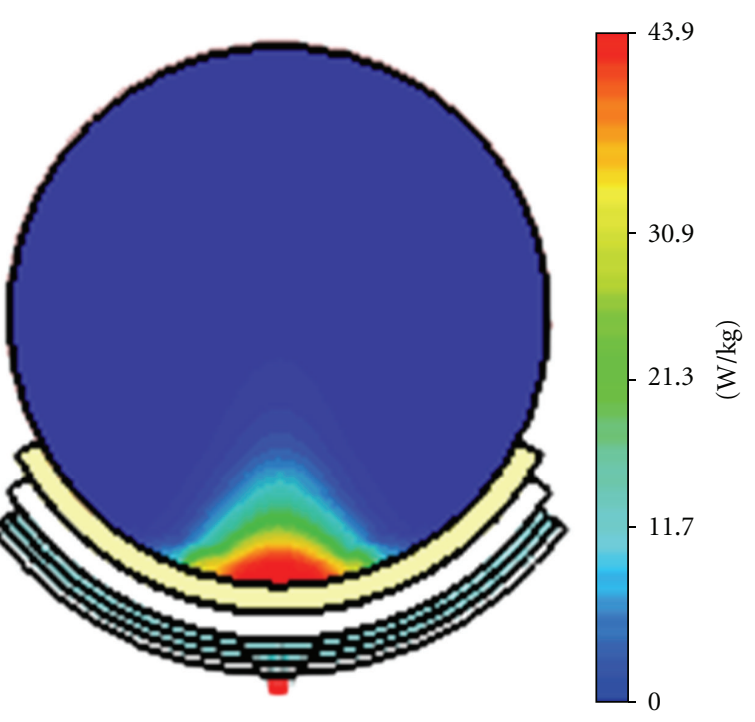

(b)

FIGURE 12: SAR distribution of the multifrequency applicator. (a) $x z$ plane, $f=915 \mathrm{MHz}$. (b) $x z$ plane, $f=2.45 \mathrm{GHz}$.

The effects of bolus thickness and body's curvature on return loss and SAR, uniformity and penetration of SAR were studied. The simulated results suggest that the designed antenna can be used on irregular surface as at the real clinical situation, and it is possible to achieve good uniformity of temperature coverage in treatment.

\section{References}

[1] D. Correia, H. P. Kok, M. De Greef, A. Bel, N. Van Wieringen, and J. Crezee, "Body conformal antennas for superficial hyperthermia: The impact of bending contact flexible microstrip applicators on their electromagnetic behavior," IEEE Transactions on Biomedical Engineering, vol. 56, no. 12, pp. 2917-2926, 2009.

[2] F. Rossetto and P. R. Stauffer, "Effect of complex bolus-tissue load configurations on SAR distributions from dual concentric conductor applicators," IEEE Transactions on Biomedical Engineering, vol. 46, no. 11, pp. 1310-1319, 1999.

[3] M. J. Ammann, S. Curto, X. L. Bao, and P. McEvoy, "Antenna design considerations for high specific absorption rate in local hyperthermia treatment," in Proceedings of the IEEE International Symposium on Antennas and Propagation and USNC/URSI National Radio Science Meeting (APSURSI '08), San Diego, Calif, USA, July 2008.

[4] T. Dř́ždal, P. Togni, and J. Vrba, "Modified microstrip ring applicator for superficial hyperthermia," in Proceedings of the 17th International Conference Radioelektronika, Brno, Czech, April 2007.

[5] Y. Gong and G. Wang, "Superficial tumor hyperthermia with flat left-handed metamaterial lens," Progress in Electromagnetics Research, vol. 98, pp. 389-405, 2009.

[6] J. Carlier, V. Thomy, J. Camart, L. Dubois, and J. Pribetich, "Dual-Mode antenna design for microwave heating and noninvasive thermometry of superficial tissue disease," IEEE Transactions on Biomedical Engineering, vol. 47, no. 11, pp. 1500-1509, 2000.
[7] P. R. Stauffer, "Radiation patterns of dual concentric conductor microstrip antennas for superficial hyperthermia," IEEE Transactions on Biomedical Engineering, vol. 46, no. 11, pp. 1310-1319, 1999.

[8] http://niremf.ifac.cnr.it/tissprop/.

[9] A. Vander Vorst, A. Rosen, and Y. Kotsuka, RF/Microwave Interaction with Biological Tissues, John Wiley \& Sons, New York, NY, USA, 2006.

[10] M. W. Dewhirst, T. L. Phillips, T. V. Samulski et al., "RTOG quality assurance guidelines for clinical trials using hyperthermia," International Journal of Radiation Oncology Biology Physics, vol. 18, no. 5, pp. 1249-1259, 1990. 

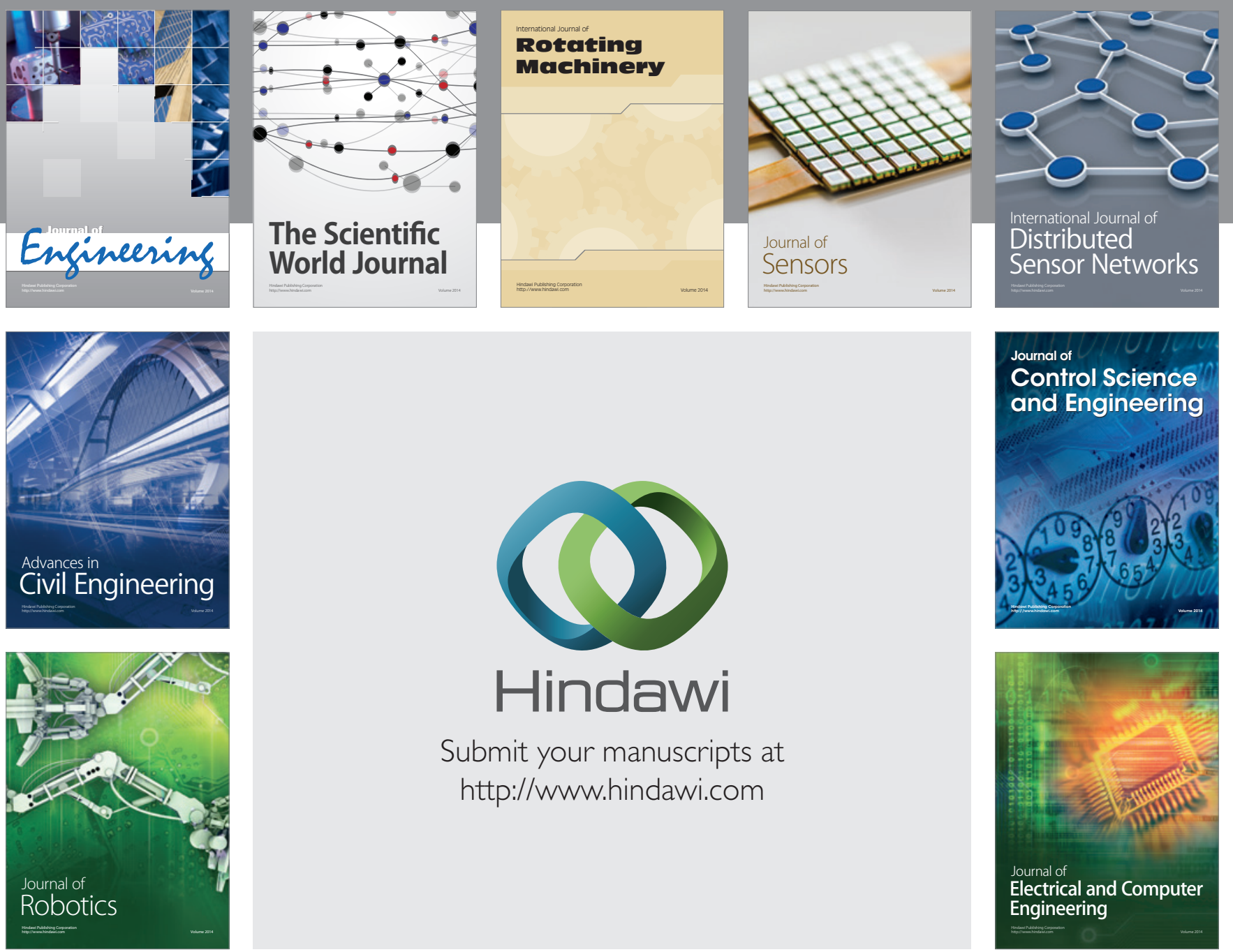

Submit your manuscripts at

http://www.hindawi.com
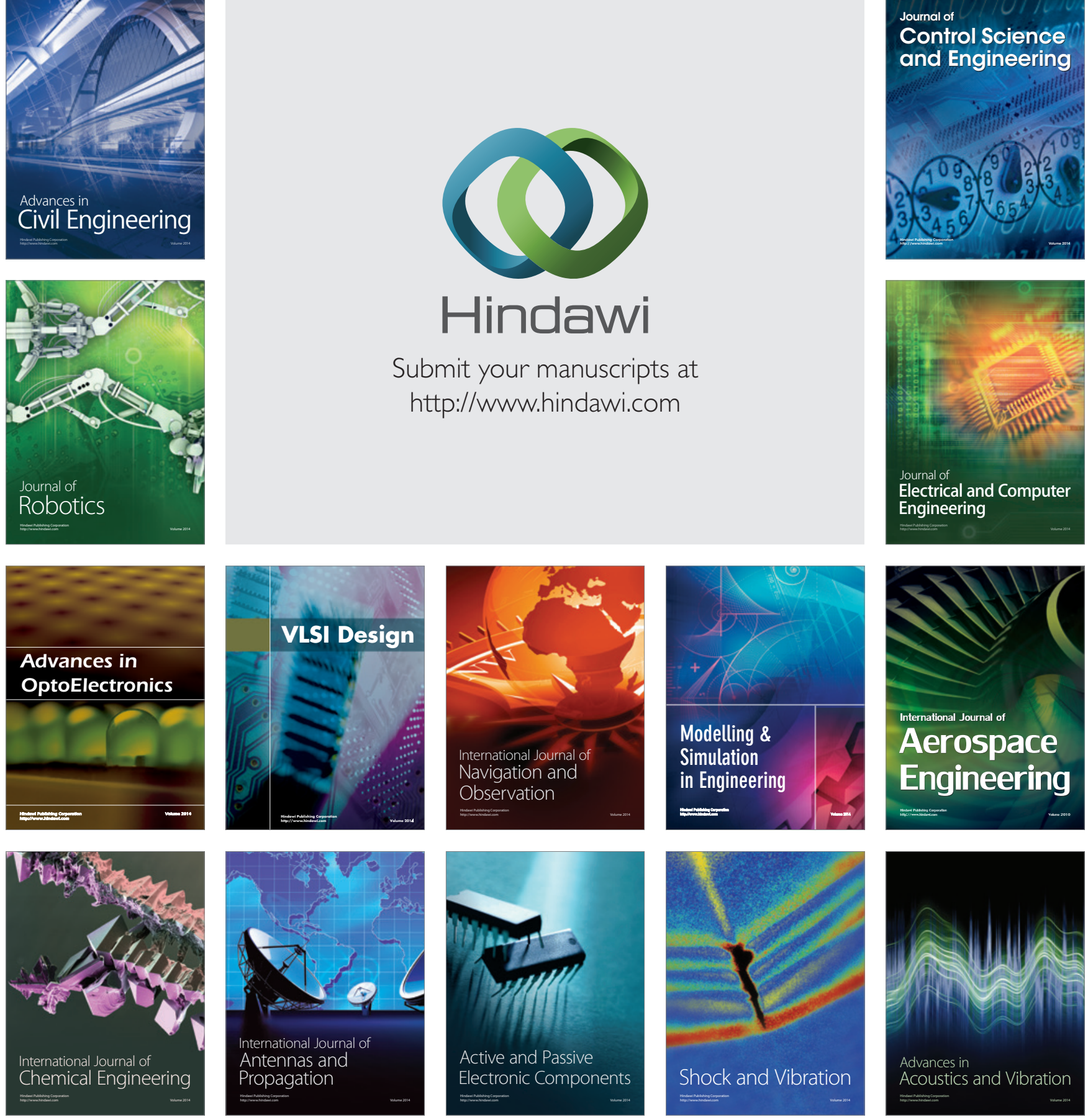